\title{
Recent advances regarding tumor microenvironment and immunotherapy in hepatocellular carcinoma
}

\author{
Wei Qin, Zhen-Yu Cao, Si-Yuan Liu, Xun-Di Xu \\ Hunan Provincial Key Laboratory of Hepatobiliary Disease Research, Division of Hepatobiliary \& Pancreatic Surgery, \\ Department of Surgery, The Second Xiangya Hospital, Central South University, Changsha 410011, Hunan, China.
}

Correspondence to: Dr. Xun-Di Xu, Hunan Provincial Key Laboratory of Hepatobiliary Disease Research, Division of Hepatobiliary \& Pancreatic Surgery, Department of Surgery, The Second Xiangya Hospital, Central South University, Changsha 410011, Hunan, China.E-mail: xuxundi@csu.edu.cn.

How to cite this article: Qin W, Cao ZY, Liu SY, Xu XD. Recent advances regarding tumor microenvironment and immunotherapy in hepatocellular carcinoma. Hepatoma Res 2020;6:24. http://dx.doi.org/10.20517/2394-5079.2020.04

Received: 20 Jan 2020 First Decision: 11 Mar 2020 Revised: 25 Mar 2020 Accepted: 10 Apr 2020 Published: 11 May 2020

Science Editors: Jia Fan, Ying-Hong Shi Copy Editor: Jing-Wen Zhang Production Editor: Tian Zhang

\begin{abstract}
Hepatocellular carcinoma (HCC) is one of the most common malignant tumors of the liver, with poor prognosis and high mortality. Traditional treatments for patients with HCC have shown poor efficacy especially for advanced liver cancer. Compared with other organs, the liver has more natural immune cells such as Kupffer cells, natural killer cells and natural killer T cells. Immunotherapy for liver cancer has become the focus in current research. The theoretical basis of immunotherapy rests on immune tolerance and suppression in the tumor microenvironment. Common immunotherapy methods include vaccines, cytokines, adoptive cell therapies, immune checkpoint inhibitors, and oncolytic viruses. Compared with traditional treatment, immunotherapy can enhance the body's immune function, delay tumor progression, and prolong survival. This article reviews the HCC microenvironment and immunotherapy both in the clinical and basic research aspects.
\end{abstract}

Keywords: Immunotherapy, hepatocellular carcinoma, microenvironment, immune

\section{INTRODUCTION}

Epidemiological data indicate that hepatocellular carcinoma (HCC) ranks fifth among malignancies, but it is the third most common cause of cancer-related death in the world. One of the major causes of HCC is persistent infection with hepatitis B virus (HBV) or hepatitis C virus (HCV). Aflatoxin exposure is also a crucial risk factor. In addition, excessive drinking, smoking, obesity, genetic factors and dietary habits are also important factors that promote the occurrence of $\mathrm{HCC}^{[1]}$.

\footnotetext{
(6) (1)

(C) The Author(s) 2020. Open Access This article is licensed under a Creative Commons Attribution 4.0 International License (https://creativecommons.org/licenses/by/4.0/), which permits unrestricted use, sharing, adaptation, distribution and reproduction in any medium or format, for any purpose, even commercially, as long as you give appropriate credit to the original author(s) and the source, provide a link to the Creative Commons license, and indicate if changes were made.
}

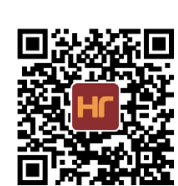


With the development of surgical techniques, HCC may be cured by surgical resection or liver transplantation in the early stage. In addition, some early malignancies may be cured by prompt local treatment such as radiofrequency ablation (RFA) or percutaneous ethanol injection treatment. Unfortunately, due to the concealed and rapid progress of HCC, most patients have lost the chances of best treatment by the initial visit. Only a fraction of patients with HCC have the opportunity for these treatments. As for the patients who are not suitable for surgery or RFA, stereotactic body radiation therapy, portal vein embolization and other liver-directed therapies have become the standard treatment means ${ }^{[2]}$. In recent years, with the great scientific and technological advances, systemic therapy has been adopted by most hepatobiliary surgeons under conditions of appropriate liver function and good physical condition.

In the past several decades, many genetic alterations in HCC have been confirmed by previous mechanism studies, such as aberrant activation of oncogenes and the inactivation of anti-oncogenes. Apart from gene mutations, changes in epigenetics such as chromatin modification, DNA methylation, gene recombination, histone modification, RNA interference and copy number variation have been proven to play a critical part in the development of primary liver cancer ${ }^{[3]}$.

The tumor microenvironment plays a vital role in tumorigenesis and cancer development and metastasis, which can be divided into an immune microenvironment characterized by immune cells and nonimmune microenvironment characterized by fibroblasts. The majority of immune cells of the tumor microenvironment include T lymphocytes, B lymphocytes, macrophages, natural killer (NK) cells and antigen-presenting cells (APCs) ${ }^{[4]}$. In the microenvironment of the liver tumor, the composition and proportion of immune cells play vital roles in the progress of tumorigenesis [Figure 1]. Compared to other organs, the liver is richer in immune cells, including natural killer T cells (NKT cells), Kupffer cells and NK cells ${ }^{[5]}$. Moreover, inactivation of immunosuppressive cytokines (such as IL-4, -5, -8, -10, etc.) and immune activating cytokines (such as TNF, IL-1, etc.) tends to produce an immunosuppressive environment. Constant exposure to antigen at higher concentrations from the gastrointestinal tract induces the liver to develop intrinsic immune tolerance and immune evasion to ward off autoimmune injury ${ }^{[6]}$. Since intrinsic immune tolerance and immune escape are often connected with HCC tumorigenesis, a growing number of studies point to immunotherapies (such as vaccines, adoptive cell therapies, immune checkpoint blockade, cytokines, etc.) targeting the microenvironment as a new strategy against hepatic cancer to bring new hope to patients with HCC. In this article, we reviewed the important role of the microenvironment in HCC tumorigenesis and the recent advances of immunotherapy in HCC.

\section{ROLE OF IMMUNE CELLS IN LIVER TUMOR MICROENVIRONMENT}

The tumor microenvironment contains a series of immune cells including NK cells, dendritic cells (DCs), macrophages, regulatory $\mathrm{T}$ cells (Tregs), neutrophils, $\mathrm{T}$ cells and eosinophils [Figure 1]. The function and number of immune cells both matter in the liver immune microenvironment, and related changes are frequently observed in the development of HCC. Multiple immune cells will promote tumor occurrence and development by activating or inhibiting various complex signaling pathways.

\section{Tumor-associated macrophages}

Previous works have established that there are monocyte-derived macrophages divided into M1 and M2 phenotypes ${ }^{[7]}$. Tumor-associated macrophages (TAMs) are a significant component of the liver microenvironment, being very important to tumor development and thus resulting in the poor outcome of HCC patients. Preclinical studies have shown that TAMs suppress the immune system and promote tumor progression through the expression of chemokines and cytokines ${ }^{[8,9]}$. It has been reported that CCL17, CCL18 and CCL22 can block the activation of cytotoxic T cells by attracting Tregs to tumor sites ${ }^{[10-12]}$. TAMs interact with bone myeloid-derived suppressor cells (MDSCs) to lower major histocompatibility complex II (MHCII), IL-6 and IL-12 levels and increase IL-10 production ${ }^{[13]}$. IL-10 produced by TAMs increases the 


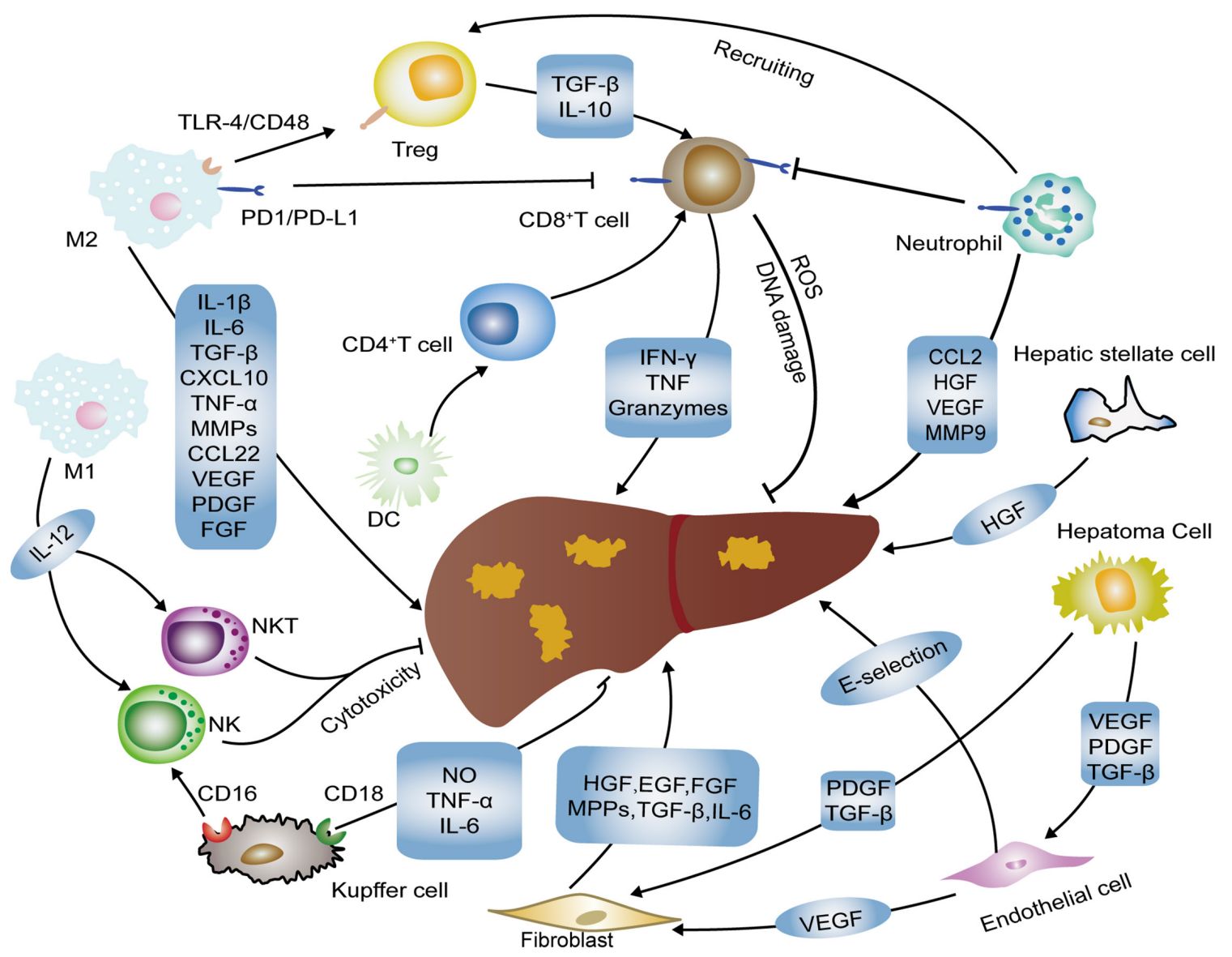

Figure 1. HCC microenvironment components and linkage. A variety of immune-related cells in the tumor microenvironment can promote or inhibit the development of hepatocellular carcinoma through various mechanisms. HCC: hepatocellular carcinoma; VEGF: vascular endothelial growth factor; NK: natural killer; DC: dendritic cell; PDGF: platelet-derived growth factor; TGF: transforming growth factor; HGF: hepatocyte growth factor; EGF: epidermal growth factor; FGF: fibroblast growth factor; MPPs: matrix metalloproteinases; NO: nitric oxide; TNF: tumor necrosis factor; NKT: natural killer T cells; ROS: reactive oxygen species

expression of FoxP3 ${ }^{+}$Tregs and then blocks $\mathrm{CD}_{4}^{+} \mathrm{CD}_{25}{ }^{-} \mathrm{T}$ cell expression, at least promoting the progression of $\mathrm{HCC}^{[14]}$.

The chemotactic migration and selective activation functions of TAMs are achieved by osteopontin expressed by HCC cells through the CSF1-CSF1R pathway ${ }^{[15]}$. Many studies indicate that TAMs release many important cytokines, including TNF- $\alpha$, IL-6, IL-1 $\beta$, and IL-23 and that they promote the expansion of Th17 cells, which protects against antitumor immunity by activating several markers ${ }^{[16,17]}$. In addition, TAMs are able to induce angiogenesis by producing angiogenic factors and matrix metalloproteinases ${ }^{[18]}$. Recently, more studies have determined that autophagy plays a key role in the functional control and immunosuppression of TAMs ${ }^{[19]}$.

\section{Tumor-associated neutrophils}

Similar to macrophages, tumor-associated neutrophils (TANs) have different effects on the biological behavior of tumors due to different degrees of polarization ${ }^{[20]}$. Recent evidence suggests that TANs can be classified into $\mathrm{N}_{1}$ (suppress tumor development) and N2 (promote tumor development) phenotypes on the basis of TGF- $\beta$ expression ${ }^{[19,20]}$. Some cytokines such as type I interferons and TGF- $\beta$ can modulate the activity of TANs ${ }^{[21]}$. Studies have confirmed that the impact of neutrophils on tumor development is regulated by $\mathrm{CD}^{+}{ }^{\mathrm{T}}$ cells ${ }^{[22]}$. 
TANs are one of the key factors for HCC progression and poor prognosis, and neutrophil-lymphocyte ratio closely correlates with tumor progression, which is a significant independent factor predicting survival after hepatectomy in patients with liver cancer ${ }^{[23,24]}$. In peripheral blood, the highest levels of the cytokines CCL17 and CCL2 are produced by peripheral blood neutrophils activated by HCC cells and TANs. The newest discovery shows that TANs mediate the intratumoral infiltration of TAMs and regulatory T cells by overproducing CCL2 and CCL17, which then contributes to HCC progression and metastasis ${ }^{[25]}$. Zhou et al. ${ }^{[25]}$ collected and analyzed HCC patients' clinical and pathological data, and the results showed that the number of $\mathrm{CCL}_{2}{ }^{+}$or $\mathrm{CCL}_{1} 7^{+}$TANs was related to tumor progression and differentiation. Moreover, these authors also found that TANs triggered the secretion of microRNA 301b-3p by releasing bone morphogenic protein 2 and transforming growth factor beta 2 (TGF 32 ) in HCC cells, and then increased the expression of HCC stem cell-like cells by inhibiting the expression of the limbic system-associated membrane protein and CYLD lysine 63 deubiquitinase genes. From this research, a positive feedback loop governing cancer stemlike cells and TANs in HCC were identified ${ }^{[26]}$. TANs play a significant role in immunosuppression in HCC, unfortunately, the exact underlying mechanisms between TANs and other molecules in HCC are not quite clear.

\section{Innate lymphocytes}

The liver is a non-lymphoid organ although possessing anti-tumor capabilities, due to containing large populations of natural lymphocytes including NK cells, NKT cells, etc. ${ }^{[27-29]}$. The activation of NK cells rely on a cascade of multiple activated and inactivated receptors ${ }^{[30]}$. In the oxygen-deficient liver environment, the function of NK cells will be impaired due to hypoxia-inducible factor $1 \alpha$ (HIF-1 $\alpha$ ), which induces changes in MHC class I polypeptide-related sequence A (MICA) ${ }^{[31]}$. HIF- $1 \alpha$ is important for regulates metabolism, cell proliferation and apoptosis of in HCC microenvironment ${ }^{[31,32]}$. In the presence of HIF-1 $\alpha$, proangiogenic genes including vascular endothelial growth factor $(V E G F)$ gene are frequently overexpressed in immune cells $^{[33]}$.

It is reported that $\alpha$-fetoprotein (AFP) can directly influence the functions of NK cells. Short exposure of NK cells to AFP can promote the IL-2 hyperresponsive phenotype and contribute to the release of IL-6, IL- $1 \beta$ and TNF- $\alpha$, which is related to a low recurrence rate and better overall survival of HCC patients with $\mathrm{HBV}^{[34,35]}$. Moreover, NK cell functions can be impaired via TGF- $ß 1, \mathrm{IL}-8$ and IL-10 released by Tregs ${ }^{[36]}$.

\section{Tregs}

Tregs belong to the subset of $\mathrm{CD}^{+}{ }^{+} \mathrm{T}$ cells, which do not merely suppress autoimmune response, but also impair the immune response against tumors ${ }^{[37,38]}$. Gao et al. ${ }^{[39]}$ demonstrated that Tregs represent an independent predictor of HCC recurrence and survival, and is related to invasiveness and intratumoral homeostasis. They also found that the combination of Treg removal and simultaneous stimulation of effector $\mathrm{T}$ cells was an effective immunotherapy to decrease recurrence and prolong postoperative survival. $\mathrm{CD}^{+}{ }^{+} \mathrm{CD} 25^{+}$Tregs were used to contribute to tumor prevention in HCC patients through various contactdependent and contact-free mechanisms. Fu et al. ${ }^{[40]}$ further demonstrated that $\mathrm{CD}_{4}{ }^{+}, \mathrm{CD} 25^{+}$and $\mathrm{FoxP}_{3}{ }^{+}$ Tregs impaired the function of $\mathrm{CDs}^{+} \mathrm{T}$ cells effector and that the number of circulating Tregs correlated with progression in HCC patients. In addition, another study showed that that compared with normal tissues, where $\mathrm{CD} 4{ }^{+} \mathrm{CD} 25^{+} \mathrm{T}$ cells were significantly increased in the area around the tumor ${ }^{[4]]}$.

\section{$\mathrm{CD}^{+}$cytotoxic T lymphocytes}

$\mathrm{CD}^{+}{ }^{+} \mathrm{T}$ cells are critical for pathogen clearance, where they contribute to the resolution of HBV and HCV infections in the liver ${ }^{[42,43]}$. Guo et al. ${ }^{[42]}$ study confirmed that Fas/FasL interactions might suppress antitumor immune responses via turnover of $\mathrm{CD}^{+} \mathrm{T}$ cells. In addition, a series of immunoregulatory elements such as IL-10, IL-2, VEGF and indoleamine-2,3-dioxygenase (IDO) play an important role in inhibiting tumorassociated antigen (TAA)-specific $\mathrm{CD}^{+} \mathrm{T}$ cell responses ${ }^{[42,44,45]}$. It has been proven that $\mathrm{CD} 14^{+} \mathrm{DCs}$ inhibit 
the in vitro response of $\mathrm{CD}^{+} \mathrm{T}$ cells by affecting IL-10 and $\mathrm{IDO}^{[46]}$. Furthermore, $\mathrm{CD} 4$ helper $\mathrm{T}$ cells are substantially important in generating functional memory CD8 $\mathrm{T}$ cells by inducing costimulatory molecules and promoting the expression of extracellular cytokines in DCs ${ }^{[47,48]}$.

\section{DCs}

NK cells are another participant in innate immunity, capable of initiating $\mathrm{T}$ cells against TAAs that are specialized APCs involved in HCC progression ${ }^{[49]}$.

In HCC, DCs can produce chemotactic cytokines, and take the initial $\mathrm{T}$ cells as the point of action to promote their aggregation and proliferation ${ }^{[50]}$. Moreover, DCs can promote the maturation of B lymphocytes, enhance the immune response mediated by antitumor antibodies, and suppress immune escape ${ }^{[51]}$. The available evidence suggests that DC maturation disorder, function decrease and reduction in peripheral blood are often observed in the HCC microenvironment, often leading to tumor development ${ }^{[52,53]}$.

In HCC, DC function is inhibited due to the production of some factors (IL-10, IL-6, etc.) in the tumor microenvironment ${ }^{[54]}$. Beckebaum et al. ${ }^{[55]}$ confirmed that IL-10 has a considerable immunosuppressive effect on circulating DCs in HCC patients. In addition, previous studies have shown that DCs can promote immunosuppression by producing IL-10 and IDO in HCC, but that depends on the expression of CTLA $4{ }^{[46]}$.

In general, in recent years, DCs have been widely used as new vaccines in the treatment of solid tumors such as liver cancer, prostate cancer, kidney cancer, melanoma, etc. ${ }^{[6,57]}$.

\section{MDSCs}

Myeloid-derived suppressor cells MDSCs comprise a mixture of macrophages, monocytes, granulocytes and DCs, which are a heterogeneous population of immature myeloid cells ${ }^{[58]}$. Some previous investigations revealed that MDSCs participate in immunosuppressive networks and are potential immunotherapy targets for HCC ${ }^{[59-62]}$. A study by Zhou et al. ${ }^{[63]}$ showed that immunosuppressed CD11 b ${ }^{+} \mathrm{CD}^{+} 3^{+}$HLA-DR $^{-}$MDSCs were stimulated and amplified by hepatic CCRK by increasing IL- 6 expression in human peripheral blood mononuclear cells. In addition, they also found that tumor-infiltrating $\mathrm{CD}_{11} \mathrm{~b}^{+} \mathrm{CD}_{33^{+}} \mathrm{HLA}^{-\mathrm{DR}^{-}} \mathrm{MDSCs}$ potently inhibited autologous $\mathrm{CD} 8^{+} \mathrm{T}$ cell proliferation in HCC patients. MDSCs express galectin- 9 and bind to TIM-3 on T cells to induce T cell apoptosis ${ }^{[64]}$.

In HCC patients, MDSC can also impair function of NK cells by inhibiting their cytotoxicity and cytokine release $^{[65]}$. Furthermore, Hu et al ${ }^{[66]}$ showed that MDSCs can inhibit the production of IL-12 induced by TLR-ligand via the expression of IL-10 and can inhibit T lymphocyte activity. In summary, MDSCs play a variety of immunosuppressive roles in HCC.

Given that MDSCs play a variety of immunosuppressive roles in HCC, the immunotherapy targeted MDSC has become a research hotspot. Some previous research has shown that the combination of radiotherapy and IL-12 (RT/IL-12) may reduce accumulation of tumor-infiltrating MDSCs and reverse the intratumoral immunotolerant state and improve the immune level in $\mathrm{HCC}^{[67]}$. In addition, targeting MDSCs and combining anti-PD-1/PD-L1 can synergistically enhance the cure of $\mathrm{HCC}^{[63,68]}$.

\section{Hepatic stellate cells, endothelial cells and kupffer cells}

In addition to that described above, hepatic stellate cells (HSC) are an important element in the microenvironment of liver tumor. Previous research has shown that HSC can secret hepatocyte growth factor/cytokines, which lead to decreased antitumor immunity function ${ }^{[69]}$. In addition, hepatocyte growth factor (HGF) secreted by activated HSC promotes the invasiveness and tumorigenicity of $\mathrm{HCC}^{[00,71]}$.

Compared with normal tissues, the endothelial cells of HCC are significantly different in molecular and functional aspects. Endothelial cells are involved in tumor neovasculature and play a significant role in 
Table 1. Major immunotherapeutic approaches for HCC

\begin{tabular}{|c|c|c|}
\hline Approach & Subject & Agent \\
\hline \multirow[t]{4}{*}{ Vaccines } & Antigen peptide & AFP, GPC3, SSX-2, Htert \\
\hline & Dendritic cells & Tumor antigens on DCs and tumor lysate on DCs \\
\hline & HCC cells & HCC cells or lysates \\
\hline & Oncolytic virus & CVV, JX-594, GLV-1h68 and G47delta \\
\hline \multirow[t]{3}{*}{ Checkpoint inhibitors } & CTLA-4 & Tremelimumab, tremelimumab with TACE or RFA \\
\hline & PD-1 & Nivolumab, pembrolizumab and pidilizumab \\
\hline & PD-L1 & Atezolizumab \\
\hline \multirow[t]{4}{*}{ Adoptive cells } & CAR-T & GPC3, GPC3 and ASGR1 \\
\hline & TILs & \\
\hline & NK cells & NK with K562-mb15-41BBL, sorafenib and NKG2D \\
\hline & $\mathrm{CIK}$ & $\mathrm{CD}^{+} / \mathrm{CD} 6^{+} \mathrm{T}$ cells, CIK combination with TACE + RFA \\
\hline
\end{tabular}

HCC: hepatocellular carcinoma; CIK: cytokine induced killer; NK: natural killer; CAR-T: chimeric antigen receptor T cell; CTLA-4: cytotoxic T lymphocyte-associated antigen-4; CVV: cowpox virus; RFA: radiofrequency ablation; TILs; tumor-infiltrating lymphocytes; DCs: dendritic cells; TACE: transcatheter arterial chemoembolization

malignant invasion and metastasis. Previous studies have shown that various angiogenic receptors are expressed in endothelial cells, such as epidermal growth factor homology domains-2 (Tie-2), VEGF receptors, platelet-derived growth factor receptor, epidermal growth factor receptor and C-X-C chemokine receptors, which promote the formation of new blood vessels ${ }^{[72,73]}$. Liver sinus endothelial cells are special endothelial cells that can collect sample portal venous blood and act as APCs to cross-prime $\mathrm{T}$ cells ${ }^{[74]}$. In addition, the synergistic induction of tumor-derived VEGF-A and prostaglandin E2 (PGE2) can reduce antitumor immune response through excessive turnover of $\mathrm{CD}^{+} \mathrm{T}$ cells ${ }^{[45]}$.

Kupffer cells are hepatocyte macrophages that form the first line of defense against pathogens and promote local tolerance ${ }^{[75]}$. When stimulated by inflammatory cytokines, Kupffer cells are also stimulated (TNF- $\alpha$, IL-1, PDGF) to produce excess osteopontin, which plays an important part in different cellular signaling pathways, promoting inflammation, tumor invasion and metastasis ${ }^{[76]}$. Kupffer cells produce large amounts of IL-6 in response to hepatocyte death, which contributes to compensatory proliferation of hepatocytes ${ }^{[77]}$. In addition, IL-10 inhibits the expression of Kupffer cell-derived inflammatory TNF- $\alpha$, and works in concert with $\mathrm{NO}$ to reduce liver inflammation ${ }^{[78]}$.

\section{CURRENT STAGES OF IMMUNOTHERAPY}

In view of the important role of the immune microenvironment in liver tumors, immunotherapy for liver cancer has become the focus in current research. According to the present study, immunotherapeutic approaches are divided into vaccines, cytokines, adoptive cell therapies, immune checkpoint inhibitors, and oncolytic viruses [Table 1].

\section{Vaccines in HCC management}

The essence of cancer vaccination is the body's own immune system activated by an antigenic substance and then attacks the tumor. With the progress of immunology and technology, tumor vaccine therapy has become the frontier in tumor treatment research. Recently, some studies showed that HCC vaccines mainly include vaccines based on antigen peptides, DCs, cancer cells and DNA.

\section{Antigen peptide vaccines}

Antigen peptide vaccines are accurate targets for HCC and are based on TAAs. Recently, the most frequently reported peptide vaccines have been AFP peptide vaccines ${ }^{[79,80]}$. AFP is a glycoprotein belonging to the albumin family, and is normally expressed in abundance in fetal blood while aberrantly expressed on the surface of HCC cells. However, due to the immune tolerance of the liver, the immune response to AFP is limited ${ }^{[81]}$. It is difficult for AFP to produce an effective immune response when it is synthesized in the 
liver. Some clinical trials based on AFP have been initiated ${ }^{[82]}$. Zhang et al. ${ }^{[82]}$ showed that cellular immune responses may be responsible for the antitumor activity against AFP-positive tumor cells in the mouse HCC model. Unfortunately, the AFP peptide vaccine also has certain limitations, where it only targets the AFPspecific immune response.

Carcinoembryonic antigen glypican-3 (GPC3) is another important antigen that targets liver cancer ${ }^{[83]}$. In 2012, a phase I clinical trial was been initiated. Thirty-three advanced HCC patients were injected with GPC3 peptide, and nineteen HCC patients showed stable disease after 2 months treatment. The study results showed that the GPC3-derived peptide vaccination not only has good immune tolerance, but also has a clear immune response and antitumor efficacy ${ }^{[84]}$.

Studies indicate that human telomerase reverse transcriptase (hTERT) is a catalytic enzyme necessary for telomere extension ${ }^{[85,86]}$. Mizukoshi et al ${ }^{[87]}$ showed that hTERT is an important target for T cell-based immunotherapy in HCC. Another study found that $71.4 \%$ of liver cancer patients acquired TERT-specific immunity and $57.1 \%$ of patients had no HCC recurrence after vaccination with hTERT461 peptide-specific T cells $^{[88]}$. SSX-2, a cancer-testis antigen, has been shown to be overexpressed in HCC patients. Recent evidence suggestw that a large number of SSX-2- and MAGE-A-specific $\mathrm{CD}^{+} \mathrm{T}$ cells can be found in $\mathrm{HCC}^{[89]}$.

DCs

DCs are the immune cells with the strongest antigen-presenting ability in the human immune system. Some cytokines such as recombinant human interleukin 4 (rhIL-4) and recombinant human granulocyte macrophage colony stimulating factor (rhGM-CSF) can activate the function of DCs, and DCs can be sensitized via the lysis of liver cancer cells. Some research has shown that immature DCs do not cause serious immune response but suppress $\mathrm{CD} 8^{+} \mathrm{T}$ cell immunity ${ }^{[90]} \cdot \mathrm{CD}^{+} \mathrm{T}$ cells and polarized $\mathrm{CD} 4^{+} \mathrm{T}$ cells are induced by mature DCs. Therefore, mature DCs should be selected as the tumor vaccine and their maturity should be evaluated ${ }^{[91]}$. In the body's immune system, the $\mathrm{CD} 4^{+} \mathrm{T} / \mathrm{CD} 8^{+} \mathrm{T}$ ratio is used to evaluate the antitumor immunity. Encouragingly, the proportion of $\mathrm{CD} 4^{+} \mathrm{T} / \mathrm{CD} 8^{+} \mathrm{T}$ has been shown to be significantly increased after DC-based immunotherapy. In addition, the latest study demonstrated that the survival rate and survival time of HCC patients were increased after DC-based immunotherapy when analyzing 1276 cases in 19 clinical trials ${ }^{[92]}$. In addition, DC-derived exosomes are a novel class of vaccines for cancer immunotherapy. AFP-rich derived exosomes can elicit a strong antigen-specific antitumor immune response, providing a cell-free vaccine option for HCC immunotherapy ${ }^{[93]}$.

However, there are many challenges in immunotherapy with DC vaccines. To resolve the problems better, some researchers combine DC-based vaccines with checkpoint inhibitors to improve efficacy. Wilgenhof et al. ${ }^{[94]}$ combined DC vaccines with an immune checkpoint cytotoxic T lymphocyte-associated antigen-4 (CTLA-4) inhibitor for advanced melanoma in phase II clinical studies. The experimental results showed that the combination of tumor vaccine and immune checkpoint inhibitor has significant advantages over single drug treatment. Furthermore, a phase I/IIa clinical study achieved encouraging results showing that the adjuvant DC vaccine for HCC was safe and well tolerated ${ }^{[95]}$.

\section{HCC cell vaccines}

HCC cells or lysates that are physically or chemically disposed to eliminate pathogenicity could be used as immunogens for tumor-specific immune responses. Nemunaitis et al. ${ }^{[96]}$ conducted a phase I trial of cellular immunotherapy using autologous whole-cell tumors $\left(\mathrm{FANG}^{\mathrm{TM}}\right)$. They observed that FANG manufacturing was successful in 7 of 8 attempts in this study. However, HCC vaccines are still in the early stage of clinical research and more studies are needed to prove their efficacy.

\section{Oncolytic virus vaccines}

The basic principle of antitumor oncolytic viruses is to expand them inside cancer cells and lyse them, eventually killing the cancer cells, and can selectively replicate and lyse in tumor cells without damaging 
Table 2. Representative clinical trials of immune checkpoints inhibitor in hepatocellular carcinoma

\begin{tabular}{|c|c|c|c|c|}
\hline Antibody features & Antibody name & Enrollment & NCT number & Status \\
\hline \multirow[t]{2}{*}{ CTLA-4 } & Tremelimumab & 433 & NCT02519348 & Ongoing \\
\hline & & 20 & NCT01008358 & Completed \\
\hline \multirow[t]{10}{*}{ PD1 } & Nivolumab & 530 & NCT03383458 & Recruiting \\
\hline & & 1097 & NCT01658878 & Completed \\
\hline & & 1723 & NCT02576509 & Ongoing \\
\hline & Pembrolizumab & 450 & NCT03062358 & Ongoing \\
\hline & & 150 & NCT02702414 & Ongoing \\
\hline & & 60 & NCT03163992 & Recruiting \\
\hline & & 30 & NCT03419481 & Recruiting \\
\hline & & 60 & NCT02595866 & Recruiting \\
\hline & Tislelizumab & 228 & NCT03419897 & Ongoing \\
\hline & & 674 & NCT03412773 & Ongoing \\
\hline \multirow[t]{5}{*}{ PD-L1 } & Durvalumab & 1310 & NCT03298451 & Ongoing \\
\hline & & 433 & NCT02519348 & Ongoing \\
\hline & Atezolizumab & 1732 & NCT03170960 & Recruiting \\
\hline & & 740 & NCT03755791 & Recruiting \\
\hline & & 480 & NCT03434379 & Recruiting \\
\hline
\end{tabular}

CTLA-4: cytotoxic T lymphocyte-associated antigen-4; PD-L1: programmed cell death-ligand 1; PD1: programmed cell death-1

normal tissue. Pexa-vec (Jx-594) is an oncolytic vaccinia virus that selectively replicates in tumor cells that overexpress thymidine kinase, thereby ensuring that the virus specifically infects HCC cells, avoiding damage to normal cells. Moreover, the combined application of JX-594 and nivolumab in the treatment of liver cancer is also being evaluated (NCT03071094). Unfortunately, the phase III trial of Pexa-Vec/Nexavar combined therapy for liver cancer failed to show efficacy (NCT02562755) ${ }^{[97]}$. Moreover, the combined application of JX-594 and nivolumab in the treatment of liver cancer is also being evaluated (NCT03071094) ${ }^{[98]}$.

The efficacy of cowpox virus (CVV) with an evolutionary tendency for cancer was studied in an animal model of metastatic HCC. The results showed that CVV may be a promising virus against metastatic HCC ${ }^{[99]}$. In addition, GLV-1h68 and G47delta have also been used for the treatment of $\mathrm{HCC}^{[100,101]}$.

Twumasi-Boateng et al. ${ }^{[102]}$ commented, "As key control points in the antitumor response continue to be deciphered, OVs will provide an increasingly important platform for bioengineers to re-wire antitumor immunity".

\section{Immune checkpoint inhibitors in HCC management}

Previous studies confirmed that immune checkpoints are frequently activated in tumor tissues compared with normal tissues and contribute to evasion of immune surveillance by tumor cells to ${ }^{[103]}$. Tumor-associated $\mathrm{T}$ cells are reactivated by immune checkpoint inhibitors, and their antitumor function is increased. At present, the immune checkpoints PD-1, CTLA-4, TIM-3, VISTA and LAG-3 are most studied ${ }^{[104-109]}$. Among them, inhibitors of PD-1 and CTLA- 4 have been approved for treating melanomas by the FDA. In addition, in the treatment of HCC, great progress has been made in recent years [Table 2].

\section{CTLA-4 inhibitors}

CTLA-4 is a transmembrane receptor for T cells, and its expression is closely related to $\mathrm{T}$ cell activation. CTLA-4 has a higher affinity with CD80 and CD86 compared with CD28. CTLA-4 can suppress the activation of $\mathrm{T}$ cell by competitive antagonism of $\mathrm{CD} 28$ binding to $\mathrm{CD} 80$ and $\mathrm{CD} 86^{[110-112]}$. Blocking the binding of CTLA-4 to its ligands can stimulate the activation and proliferation of immune cells to induce or enhance the immune response.

Tremelimumab is a monoclonal antibody that targets CTLA4. In 2013, a clinical trial of tremelimumab enrolled 21 patients with chronic hepatitis C with Child-Pugh A or B cirrhosis and advanced HCC ${ }^{[105]}$. In 
this study, the HCC patients were administered tremelimumab intravenously at $15 \mathrm{mg} / \mathrm{kg}$ every 90 days until tumor development or severe toxicity. The results showed a partial response rate of $17.6 \%$ and disease control rate of $76.4 \%$, and $45 \%$ of the patients had stable disease for more than 6 months after treatment with tremelimumab ${ }^{[105]}$. In a phase I/II trial, tremelimumab combined with TACE or RFA were used to treated HCC. Thirty-two patients with HCC were enrolled, patients received different doses of tremelimumab (3.5 and $10 \mathrm{mg} / \mathrm{kg}$ i.v.) every 4 weeks for 6 doses and infusion for the 3 months until non-treatment criteria were reached. Subtotal RFA or chemical ablation was performed after tremelimumab. The results showed that tremelimumab combined with RFA can result in the accumulation of intratumoral $\mathrm{CD} 8^{+} \mathrm{T}$ cells, and doselimiting toxicities were not observed ${ }^{[113]}$.

\section{$P D-1$ and $P D-L 1$ inhibitors}

Some investigators have found that DCs, NK cells, B cells and mononuclear cells often show increased expression of $\mathrm{PD}-1^{[114]}$. PD-1, a member of the CD28 superfamily plays a key role in delivering co-inhibitory signals to TCR receptors ${ }^{[115]}$. Receptor binding to PD-L1 and PD-L2 were blocked by PD-1 inhibitors, resulting in $\mathrm{T}$ cells exerting normal efficacy against tumors ${ }^{[116]}$. In cancer cells, PD-L1/PD-1 signals are activated by PD-L1 or PD-L2, allowing them to evade immune surveillance ${ }^{[117]}$.

Nivolumab, a monoclonal antibody targeting PD-1, has been investigated for HCC treatment. Recently, a phase $1 / 2$ study in patients with HCC was used to assess the safety and efficacy of nivolumab in treating HCC. A total of 212 patients received nivolumab, $3 \mathrm{mg} / \mathrm{kg}$ every 2 weeks. The statistical results showed that the objective response rate was $16 \%$, while disease control rate was $68 \%$, and the 6 -month survival rate was $82.5 \%^{[118]}$. In advanced HCC patients, the safety and effectiveness of nivolumab were also assessed. In the 49 advanced HCC patients involved in a clinical trial, an objective response rate of $10 \%$ and disease control rate of $55 \%$ were seen after treatment with nivolumab for 7 months ${ }^{[119]}$. Therefore, nivolumab shows good safety for patients with advanced HCC and has the potential to treat patients with advanced HCC. In view of those results, nivolumab was approved for the treatment of HCC patients with poor treatment after sorafenib.

Pembrolizumab is an IgG4 monoclonal antibody that targets the PD-1 receptor. In a phase II trial (KEYNOTE-224), 104 advanced HCC patients were enrolled, who were given $200 \mathrm{mg}$ pembrolizumab injected every 3 weeks for about 2 years or until inappropriate. The results showed that there was objective response in 18 patients and stable disease rate of $44 \%$, in the 104 patients studied. Statistical analyses indicated that pembrolizumab was also effective in advanced HCC patients treated with sorafenib ${ }^{[120]}$. A randomized phase III trial was conducted in 413 patients with advanced $\mathrm{HCC}^{[121]}$. In this study, improvement of overall survival, progression-free survival (PFS), overall response rate, and duration of response were observed in patients with pembrolizumab compared with the KEYNOTE224 study. The results showed that a good risk-benefit ratio for pembrolizumab in advanced HCC was also supported.

In 2008, 26 HCC patients who could not be resected or who showed metastasis were studied to determine the safety of atezolizumab, which targets PD- $1_{1}^{[122]}$. Atezolizumab $(1200 \mathrm{mg})$ and bevacizumab $(15 \mathrm{mg} / \mathrm{kg})$ were injected via i.v. every 3 weeks. The results demonstrated a response rate of $62 \%$ and that this atezolizumab + bevacizumab combination was safe and well tolerated. The basic finding of this research was that the effects of atezolizumab were enhanced by anti-VEGF therapy. In addition, MEF2D can increase the expression of PD-L1 and inhibit antitumor immunity mediated by $\mathrm{CD}^{+} \mathrm{T}$ cells ${ }^{[123]}$.

Although immune checkpoint inhibitors have shown good efficacy in the treatment of HCC, they have limited efficacy in advanced HCC patients. The combined use of immune checkpoint inhibitors is expected to produce a synergistic effect and achieve better results. Selective clinical trials of combination immunotherapy agents in HCC are described in Table 3. In HCC patients with chronic HCV infection, the amount of $\mathrm{CD}^{+}$ $\mathrm{T}$ cells increased, but cell activity remained unchanged after blocking PD-L1/PD-1 or CTLA4. However, 
Table 3. Selective clinical trials of combination immunotherapy agents in HCC

\begin{tabular}{|c|c|c|c|c|}
\hline Antibody features & Antibody name & Enrollment & NCT number & Status \\
\hline \multirow[t]{2}{*}{ CTLA-4 and PD1 } & Nivolumab, ipilimumab & 45 & NCT03222076 & Recruiting \\
\hline & & 50 & NCT03203304 & Recruiting \\
\hline CTLA-4 + chemoembolization & Tremelimumab, TACE & 61 & NCT01853618 & Completed \\
\hline CTLA-4 + PD-L1 & Durvalumab, remelimumab & 433 & NCT02519348 & Ongoing \\
\hline CTLA-4 + PD-1 + anti-OX40 & CTLA-4, PD-1, INCAGN01949 & 52 & NCT03241173 & Completed \\
\hline CTLA-4 + PD1 + ablative & Durvalumab, tremelimumab, ablative & 90 & NCT02821754 & Recruiting \\
\hline PD-1 + TIL & TIL, PD-1 & 332 & NCT01174121 & Recruiting \\
\hline \multirow[t]{2}{*}{ PD-1 + neoadjuvant } & Nivolumab, cabozantinib & 15 & NCT03299946 & Ongoing \\
\hline & Pembrolizumab, sorafenib & 27 & NCT03211416 & Recruiting \\
\hline PD-1 + oncolytic & Nivolumab, Pexa Vec & 30 & NCT03071094 & Ongoing \\
\hline PD-1 + radiation & Nivolumab, SIRT & 40 & NCT03380130 & Ongoing \\
\hline PD-1 + TGF- $\beta$ receptor I kinase inhibitor & Nivolumab, galunisertib & 75 & NCT02423343 & Ongoing \\
\hline \multirow[t]{4}{*}{$P D-1+T K I$} & Nivolumab, lenvatinib & 30 & NCT03418922 & Ongoing \\
\hline & Pembrolizumab, lenvatinib & 104 & NCT03006926 & Ongoing \\
\hline & Nivolumab, cabozantinib & 15 & NCT03299946 & Ongoing \\
\hline & Pembrolizumab, regorafenib & 57 & NCT03347292 & Recruiting \\
\hline \multirow[t]{5}{*}{ PD-1 + radioembolization } & Nivolumab, yttrium-90 & 35 & NCT02837029 & Recruiting \\
\hline & Yttrium-90, nivolumab & 40 & NCT03380130 & Ongoing \\
\hline & & 40 & NCT03033446 & Recruiting \\
\hline & Pembrolizumab, SBRT & 30 & NCT03316872 & Recruiting \\
\hline & Pembrolizumab, yttrium-90 & 30 & NCT03099564 & Recruiting \\
\hline PD-1 + chemotherapy & Nivolumab, sorafenib & 40 & NCT03439891 & Recruiting \\
\hline PD-1 + immunomodulator & Nivolumab, CC-122 (avadomide) & 21 & NCT02859324 & Ongoing \\
\hline PD-1 + transarterial chemoembolization & Nivolumab, Ddeb-TACE & 14 & NCT03143270 & Recruiting \\
\hline PD-1 + anti-CCR4 antibody & Nivolumab, mogamulizumab & 114 & NCT02705105 & Completed \\
\hline PD-1 + anti-VEGF & Nivolumab, bevacizumab & 1 & NCT03382886 & Terminated \\
\hline PD-1 + curative resection & Toripalimab, surgery & 402 & NCT03859128 & Recruiting \\
\hline PD-1 + curative resection or ablation & Pembrolizumab & 950 & NCT03867084 & Recruiting \\
\hline PD-L1 + small molecule DNA & Durvalumab, guadecitabine (SGI-110) & 90 & NCT03257761 & Recruiting \\
\hline PD-L1 + anti-VEGFR2 & Durvalumab, ramucirumab (LY3009806) & 114 & NCT02572687 & Ongoing \\
\hline PD-L1 + anti-VEGF & Atezolizumab, bevacizumab & 430 & NCT02715531 & Ongoing \\
\hline \multirow[t]{2}{*}{ PD-L1 + TKI } & Avelumab, regorafenib & 362 & NCT03475953 & Recruiting \\
\hline & Avelumab, axitinib & 22 & NCT03289533 & Completed \\
\hline
\end{tabular}

HCC: hepatocellular carcinoma; SIRT: selective internal radiation therapy; VEGF: vascular endothelial growth factor; VEGFR: VEGF receptors; SBRT: stereotactic body radiation therapy; CTLA-4: cytotoxic T lymphocyte-associated antigen-4; TIL: tumor infiltrating lymphocytes; OX40: tumor necrosis factor receptor superfamily member 4; TGF: transforming growth factor; TKI: tyrosine kinase inhibitor; PD-L1: programmed cell death-ligand 1; PD-1: pro-grammed cell death-1; CCR4: CC-chemokine receptor 4; TACE: transcatheter arterial chemoembolization

combined use of CTLA4 and PD-L1 inhibitors can reverse the instability of $\mathrm{CD} 8^{+} \mathrm{T}$ cells and enhance intrahepatic HCV-specific CD8 and CD4 T cell cytokine response. Moreover, in the acute hepatitis C phase, the combination of PD-1/CTLA-4 inhibitors can reverse HCV-specific $\mathrm{CD}^{+}{ }^{+} \mathrm{T}$ cell dysfunction ${ }^{[124]}$. Interestingly, after the clearance of $\mathrm{HCV}, \mathrm{CD}^{+} \mathrm{T}$ cell proliferative ability can be restored preferentially under the action of immune checkpoint inhibitors ${ }^{[125]}$. In addition, Stein et al ${ }^{[126]}$ combined the PD-L1 monoclonal antibody atezolizumab and bevacizumab to treat patients with advanced HCC (NCT02715531). Moreover, the efficacy of immune checkpoint inhibitors (ipilimumab and nivolumab) combined with liver resection is being evaluated (NCT03682276, NCT03510871) ${ }^{[98]}$. As new adjuvant therapies, the curative effect of checkpoint inhibitors is also being evaluated in HCC patients undergoing surgical resection (e.g., NCT03859128 and NCT03847428) ${ }^{[98]}$.

Although many studies have reported that immune checkpoint inhibitors are showing encouraging results in the treatment of HCC, there are still potentially serious adverse reactions. PD-1 inhibitors block the interaction between PD-1 and PD-L1 and also inhibit T cells and APCs. PD-1/PD-L1 monoclonal antibodies 
cannot promote $\mathrm{T}$ cells to attack tumor cells ${ }^{[127,128]}$. Existing studies suggest that it is only effective for some patients, and a part of patients will get worse after this kind of treatment, so the treatment strategy for advanced HCC also needs to be optimized.

\section{Adoptive cell immunotherapy}

Adoptive cell immunotherapy is a special therapy including active specific immunotherapy and passive immunotherapy. In this type of therapy, cancer cells are killed by using patients' own lymphocytes. Chimeric antigen receptor $\mathrm{T}$ cell immunotherapy (CAR-T), NK cells, tumor-infiltrating lymphocytes (TILs) and cytokine induced killer (CIK) cells constitute adoptive cell immunotherapy in HCC.

\section{$C A R-T$}

CAR-T cells are a special type of transgenic T lymphocytes that specifically recognize TAAs and improve the targeting of effector $\mathrm{T}$ cells and break host immune tolerance ${ }^{[129]}$. A previous study confirmed that an intracellular signaling domain, extracellular antigen-binding domain, and an extracellular hinge area constitute the basic structure of CARs ${ }^{[130]}$. The intracellular signaling domain and extracellular antigenbinding domain are connected by the extracellular hinge area. It is the hinge area that confers high activity on the extracellular antigen-binding domain. Although CAR-T cell immunity has become a research hotspot in the application of solid tumors, more studies on HCC are still in the basic research stage, and the key point of technology lies in the selection of tumor-specific antigens. GPC3 is located on the cell surface and is a member of the glypican family of heparan sulfate. A previous study reported that GPC3 is a TAA and overexpressed in HCC compared with normal tissues. Gao et al. ${ }^{[131]}$ found that GPC3-positive HCC cells could be lysed by GPC3-targeted CAR-T cells and that the number of lysed tumor cells correlated with the expression of GPC3. Liu et al. ${ }^{[132]}$ recently stated, "The inducibly expressed IL-12-armored GPC3-CAR-T cells could broaden the application of CAR-T-based immunotherapy to patients intolerant of lymphodepletion chemotherapy and might provide an alternative therapeutic strategy for patients with $\mathrm{GPC}^{+}{ }^{+}$cancers".

Asialoglycoprotein receptor 1 (ASGR1) mediates the transport of targeted therapeutic molecules to the liver, specifically expressed on liver parenchymal cells. GPC3 and ASGR1 make a suitable target combination for dual-targeted CAR-T cells. Chen et al. ${ }^{[133]}$ surveyed data and found that the risk of on-target, off-tumor toxicity may be reduced when using $\mathrm{T}$ cells with two complementary CARs against GPC3 and ASGR1. Recently, $13 \mathrm{GPC}^{+}{ }^{+} \mathrm{HCC}$ patients were enrolled a phase I trial, where all patients who received GPC3 CAR-T treatment had no dose-limiting toxicity and tolerated the treatment well. The study results showed that GPC3 CAR-T treatment was feasible and safe for Chinese patients with $\mathrm{GPC}^{+}{ }^{+} \mathrm{HCC}(\mathrm{NCT} 02395250)^{[134]}$. With the application of CAR-T cells in the clinic, the safety of CAR-T cells has begun to attract people's attention. MacKay et al. ${ }^{[135]}$ noted, "Immune-cell failure is a major challenge for CAR therapies, and its mechanism remains to be investigated". In addition, immune rejection and off-target effects of CAR-T cells also need to be resolved ${ }^{[136]}$.

CIK cells

CIK cells are a new type of non-MHC-restricted immunocompetent cells mainly including $\mathrm{CD}^{+} / \mathrm{CD} 56$ cells, $\mathrm{CD}_{3}{ }^{-} / \mathrm{CD} 56^{+} \mathrm{NK}$ cells, $\mathrm{CD}^{+} / \mathrm{CD} 56^{+} \mathrm{T}$ cells, etc., among which $\mathrm{CD}^{+} / \mathrm{CD} 56^{+} \mathrm{T}$ cells are the main effector cells ${ }^{[137,138]}$. Preclinical trials have shown that CIK cells have high activity against HCC cells in vitro. In addition, Pan et al ${ }^{[139]}$ investigated the effect of CIK as adjuvant therapy on overall survival and relapsefree survival of HCC patients who received surgical treatment. Survival analysis showed that compared with hepatectomy alone, median overall survival and PFS were clearly prolonged in the hepatectomy/ CIK combination group (41, 16 months vs. 28, 12 months, respectively). The safety and efficacy of CIK cell immunotherapy were investigated in a phase III clinical trial in which 230 HCC patients treated with RFA, surgical resection or percutaneous ethanol injection were randomly injected with $6.4 \times 10^{9}$ autologous CIK cells (16 times during 60 weeks) or had no immunotherapy. The median time of recurrence-free survival in 
the immunotherapy group was clearly longer than control group (44 months $v s .30$ months). Cancer-related death was also lower in the CIK group than in the no immunotherapy group $(P=0.02) ; 17 \%$ of patients experienced adverse reactions related to CIK cytokines, but there was no difference in severe adverse events $^{[140]}$.

In addition, the efficacy and safety of the combination of CIK cells with liver-directed therapies in HCC were also evaluated. In a study that evaluated CIK cells combined with TACE + RFA in HCC patients. overall efficacy in the TACE + RFA + CIK group was better than in the TACE + RFA group (76.5\% vs. 79.8\%). Kaplan-Meier analysis indicated that the overall survival rate of the TACE + RFA + CIK treatment group was significantly prolonged (56 months vs. 31 months, $P=0.001)^{[141]}$. In another study, HCC patients with ChildPugh scores of A or B and without prior treatment were enrolled. One group $(n=66)$ received CIK treatment and standard treatment, while another group $(n=66)$ received standard treatment only. The results showed that overall survival and PFS were significantly prolonged after treatment with CIK cells in patients who were not suitable for surgery ${ }^{[142]}$. Furthermore, one study found that targeting MDSCs is a good strategy to enhance the antitumor efficacy of CIKs for the treatment of patients with $\mathrm{HCC}^{[143]}$.

Although more and more studies have shown that CIK cells makes up a significant part of HCC treatment, only a portion of $\mathrm{T}$ cells can provide a full antitumor function because of immune escape mechanisms and lack of specific tumor antigens.

\section{TILs}

TILs are isolated from tumor tissue and induced by IL-2 in vitro. TILs are relatively rare in HCC, but they play an important role in tumor recurrence in patients. A phase I clinical trial indicated that immunotherapy with autologous TILs could be successfully performed with low toxicity ${ }^{[144]}$. In another randomized clinical trial, 76 HCC patients were enrolled and the ratio of postoperative recurrence was significantly lower in the group using IL-2 to activate lymphocytes compared to the control group ${ }^{[145]}$. Furthermore, the functions of tumor-infiltrating $\mathrm{T}$ cells were restored via the antibodies targeting immune checkpoints ${ }^{[146]}$. Until now, the widespread use of TIL immunotherapy has been limited, mainly because of difficulties in purification and amplification.

\section{NK cells}

NK cells belong to innate immune cells, and the main feature is that they can directly destroy tumor cells without prior stimulation. Preclinical experiments showed that CXCR6 can inhibit hepatocarcinogenesis by promoting natural killer $\mathrm{T}$ cell- and $\mathrm{CD}^{+} \mathrm{T}$ cell-dependent control of senescence ${ }^{[147]}$. Another study also confirmed that expanded activated NK cells are highly cytotoxic to HCC cells. The function of NK cells against HCC were enhanced by the expression of NKG2D-CD3ל-DAP10 ${ }^{[148]}$. Tan et al ${ }^{[149]}$ reported that LrNK cells were observed to be present in liver cancer, often showing abnormal function. Moreover, this dysfunction is caused by Tim-3-mediated PI3K/mTORC1 interference. However, there is still a lack of clinical trials of NK cells in the treatment of HCC, so more clinical studies are urgently needed.

\section{SUMMARY AND FUTURE EXPECTATIONS OF IMMUNOTHERAPY IN HCC}

With the development of molecular biotechnology and tumor immunology, immunotherapy has been an important part in the mode of combined therapy of tumors. Along with the gradually deepened study of molecular biology and molecular immunology, T cells have an important influence on tumor immunity in the hepatic microenvironment. Recently, there have been a large number of studies on HCC immunotherapy, and some of them have achieved important positive results. At present, many preclinical studies demonstrate that vaccine therapy, adoptive cell therapy and immune checkpoint inhibitors make up a significant part in inhibiting the growth and development of HCC. Moreover, more clinical trials of immunotherapy for liver cancer are being conducted. In early clinical trials, tremelimumab, nivolumab, pembrolizumab and 
atezolizumab are targeting PD-1/PD-L1 or CTLA-4, and there have been encouraging results for a variety of tumors. However, phase III clinical research is still lacking, and more clinical research is urgently needed.

In addition, the results of the present study indicate that the effect of single immunotherapy on liver cancer remains limited. The indication of immunotherapy in HCC may depend on combination therapies. Combination of liver-targeted therapy and immunotherapy can enhance tumor and systemic immune response. In conclusion, the advent of immunotherapy revolutionized cancer therapy and brought treatment for HCC to a brand-new period.

\section{DECLARATIONS}

\section{Authors' contributions}

Study concept and design: $\mathrm{Xu} \mathrm{XD}$

Literature search: Qin W

Drafting of the manuscript: Qin W, Cao ZY, Liu SY

Critical revision of the manuscript for important intellectual content: $\mathrm{Xu} \mathrm{XD}$

\section{Availability of data and materials}

Not applicable.

\section{Financial support and sponsorship}

This study was funded by the National Natural Science Foundation of China (grant number 81670111).

\section{Conflicts of interest}

All authors declared that there are no conflicts of interest.

\section{Ethical approval and consent to participate}

Not applicable.

\section{Consent for publication}

Not applicable.

\section{Copyright}

(C) The Author(s) 2020.

\section{REFERENCES}

1. Akinyemiju T, Abera S, Ahmed M, Alam N, Alemayohu MA, et al.; Global Burden of Disease Liver Cancer Collaboration. The burden of primary liver cancer and underlying etiologies from 1990 to 2015 at the global, regional, and national level: results from the global burden of disease study 2015. JAMA Oncol 2017;3:1683-91.

2. Forner A, Reig M, Bruix J. Hepatocellular carcinoma. Lancet 2018;391:1301-14.

3. Fujimoto A, Totoki Y, Abe T, Boroevich KA, Hosoda F, et al. Whole-genome sequencing of liver cancers identifies etiological influences on mutation patterns and recurrent mutations in chromatin regulators. Nat Genet 2012;44:760-4.

4. Hilmi M, Vienot A. Immune therapy for liver cancers. Cancers (Basel) 2019;12:77.

5. Gao B, Jeong WI, Tian Z. Liver: an organ with predominant innate immunity. Hepatology 2008;47:729-36.

6. Shalapour S, Lin XJ, Bastian IN, Brain J, Burt AD, et al. Inflammation-induced IgA $\mathrm{A}^{+}$cells dismantle anti-liver cancer immunity. Nature 2017;551:340-5.

7. Movahedi K, Laoui D, Gysemans C, Baeten M, Stange G, et al. Different tumor microenvironments contain functionally distinct subsets of macrophages derived from Ly6C(high) monocytes. Cancer Res 2010;70:5728-39.

8. Mantovani A, Allavena P. The interaction of anticancer therapies with tumor-associated macrophages. J Exp Med 2015;212:435-45.

9. Ye YC, Zhao JL, Lu YT, Gao CC, Yang Y, et al. NOTCH signaling via WNT regulates the proliferation of alternative, CCR2independent tumor-associated macrophages in hepatocellular carcinoma. Cancer Res 2019;79:4160-72.

10. Zhu F, Li X, Chen S, Zeng Q, Zhao Y, et al. Tumor-associated macrophage or chemokine ligand CCL17 positively regulates the tumorigenesis of hepatocellular carcinoma. Med Oncol 2016;33:17.

11. Zhou SL, Zhou ZJ, Hu ZQ, Huang XW, Wang, Z, et al. Tumor-associated neutrophils recruit macrophages and T-regulatory cells to 
promote progression of hepatocellular carcinoma and resistance to sorafenib. Gastroenterology 2016;150:1646-58.e17.

12. Li ZQ, Wang HY, Zeng QL, Yan JY, Hu YS, et al. p65/miR-23a/CCL22 axis regulated regulatory $\mathrm{T}$ cells recruitment in hepatitis B virus positive hepatocellular carcinoma. Cancer Med 2020;9:711-23.

13. Zhou J, Ding T, Pan W, Zhu LY, Li L, et al. Increased intratumoral regulatory T cells are related to intratumoral macrophages and poor prognosis in hepatocellular carcinoma patients. Int J Cancer 2009;125:1640-8.

14. Sharma S, Khosla R, David P, Rastogi A, Vyas A, et al. CD4 $4^{+} \mathrm{CD} 25^{+} \mathrm{CD} 127$ (low) regulatory $\mathrm{T}$ cells play predominant anti-tumor suppressive role in hepatitis B virus-associated hepatocellular carcinoma. Front Immunol 2015;6:49.

15. Zhu Y, Yang J, Xu D, Gao XM, Zhang Z, et al. Disruption of tumour-associated macrophage trafficking by the osteopontin-induced colony-stimulating factor-1 signalling sensitises hepatocellular carcinoma to anti-PD-L1 blockade. Gut 2019;68:1653-66.

16. Kuang DM, Peng C, Zhao Q, Wu Y, Chen MS, et al. Activated monocytes in peritumoral stroma of hepatocellular carcinoma promote expansion of memory T helper 17 cells. Hepatology 2010;51:154-64.

17. Fu Y, Liu S, Zeng S, Shen H. From bench to bed: the tumor immune microenvironment and current immunotherapeutic strategies for hepatocellular carcinoma. J Exp Clin Cancer Res 2019;38:396.

18. Darvishi B, Majidzadeh AK, Ghadirian R, Mosayebzadeh M, Farahmand L. Recruited bone marrow derived cells, local stromal cells and IL-17 at the front line of resistance development to anti-VEGF targeted therapies. Life Sci 2019;217:34-40.

19. Chang CP, Su YC, Lee PH, Lei HY. Targeting NFKB by autophagy to polarize hepatoma-associated macrophage differentiation. Autophagy 2013;9:619-21.

20. Nicolas-Avila JA, Adrover JM, Hidalgo A. Neutrophils in homeostasis, immunity, and cancer. Immunity 2017;46:15-28.

21. Andzinski L, Kasnitz N, Stahnke S, Wu CF, Gereke M, et al. Type I IFNs induce anti-tumor polarization of tumor associated neutrophils in mice and human. Int J Cancer 2016;138:1982-93.

22. Michaeli J, Shaul ME, Mishalian I, Hovav AH, Levy L. Tumor-associated neutrophils induce apoptosis of non-activated CD8 T-cells in a TNFalpha and NO-dependent mechanism, promoting a tumor-supportive environment. Oncoimmunology 2017;6:e1356965.

23. Margetts J, Ogle LF, Chan SL, Chan AWH, Chan KCA, et al. Neutrophils: driving progression and poor prognosis in hepatocellular carcinoma? Br J Cancer 2018;118:248-57.

24. Mano Y, Shirabe K, Yamashita Y, Harimoto N, Tsujita E, et al. Preoperative neutrophil-to-lymphocyte ratio is a predictor of survival after hepatectomy for hepatocellular carcinoma: a retrospective analysis. Ann Surg 2013;258:301-5.

25. Zhou SL, Zhou ZJ, Hu ZQ, Huang XW, Wang Z, et al. Tumor-associated neutrophils recruit macrophages and T-regulatory cells to promote progression of hepatocellular carcinoma and resistance to sorafenib. Gastroenterology 2016;150:1646-58.e17.

26. Zhou SL, Yin D, Hu ZQ, Luo CB, Zhou ZJ, et al. A positive feedback loop between cancer stem-like cells and tumor-associated neutrophils controls hepatocellular carcinoma progression. Hepatology 2019;70:1214-30.

27. Robinson MW, Harmon C, O'Farrelly C. Liver immunology and its role in inflammation and homeostasis. Cell Mol Immunol 2016;13:267-76

28. Sundstrom P, Szeponik L, Ahlmanner F, Sundquist M, Wong JSB, et al. Tumor-infiltrating mucosal-associated invariant T (MAIT) cells retain expression of cytotoxic effector molecules. Oncotarget 2019;10:2810-23.

29. Gajewski TF, Schreiber H, Fu YX. Innate and adaptive immune cells in the tumor microenvironment. Nat Immunol 2013;14:1014-22.

30. Parodi M, Raggi F, Cangelosi D, Manzini C, Balsamo M, et al. Hypoxia modifies the transcriptome of human NK cells, modulates their immunoregulatory profile, and influences NK cell subset migration. Front Immunol 2018;9:2358.

31. Sheppard S, Ferry A, Guedes J, Guerra N. The paradoxical role of NKG2D in cancer immunity. Front Immunol 2018;9:1808.

32. Chambers AM, Lupo KB, Matosevic S. Tumor microenvironment-induced immunometabolic reprogramming of natural killer cells. Front Immunol 2018;9:2517.

33. Dengler VL, Galbraith M, Espinosa JM. Transcriptional regulation by hypoxia inducible factors. Crit Rev Biochem Mol Biol 2014;49:1-15.

34. Vujanovic L, Stahl EC, Pardee AD, Geller DA, Tsung A, et al. Tumor-derived alpha-fetoprotein directly drives human natural killercell activation and subsequent cell death. Cancer Immunol Res 2017;5:493-502.

35. Sun C, Sun H, Zhang C, Tian Z. NK cell receptor imbalance and NK cell dysfunction in HBV infection and hepatocellular carcinoma. Cell Mol Immunol 2015;12:292-302.

36. Cai L, Zhang Z, Zhou L, Wang H, Fu J, et al. Functional impairment in circulating and intrahepatic NK cells and relative mechanism in hepatocellular carcinoma patients. Clin Immunol 2008;129:428-37.

37. Fan Y, Gao Y, Rao J, Wang K, Zhang F, et al. YAP-1 promotes tregs differentiation in hepatocellular carcinoma by enhancing TGFBR2 transcription. Cell Physiol Biochem 2017;41:1189-98.

38. Wu R, Liu C, Deng X, Chen L, Hao S, et al. Enhanced alleviation of aGVHD by TGF-beta1-modified mesenchymal stem cells in mice through shifting MPhi into M2 phenotype and promoting the differentiation of Treg cells. J Cell Mol Med 2020;24:1684-99.

39. Gao Q, Qiu SJ, Fan J, Zhou J, Wang XY, et al. Intratumoral balance of regulatory and cytotoxic T cells is associated with prognosis of hepatocellular carcinoma after resection. J Clin Oncol2007;25:2586-93.

40. Fu J, Xu D, Liu Z, Shi M, Zhao P, et al. Increased regulatory T cells correlate with CD8 T-cell impairment and poor survival in hepatocellular carcinoma patients. Gastroenterology 2007;132:2328-39.

41. Yang XH, Yamagiwa S, Ichida T, Matsuda Y, Sugahara S, et al. Increase of CD4 $4^{+} \mathrm{CD} 25^{+}$regulatory T-cells in the liver of patients with hepatocellular carcinoma. J Hepatol 2006;45:254-62.

42. Guo CL, Yang XH, Cheng W, Xu Y, Li JB, et al. Expression of Fas/FasL in CD8 ${ }^{+} \mathrm{T}$ and $\mathrm{CD}^{+}{ }^{+}$Foxp3 ${ }^{+}$Treg cells--relationship with apoptosis of circulating CD8 ${ }^{+} \mathrm{T}$ cells in hepatocellular carcinoma patients. Asian Pac J Cancer Prev 2014;15:2613-8.

43. Huang CY, Wang H, Liao W, Han F, Li YQ, et al. Transforming growth factor beta is a poor prognostic factor and inhibits the favorable prognostic value of CD8 ${ }^{+}$CTL in human hepatocellular carcinoma. J Immunother 2017;40:175-86.

44. Sun Z, Ren Z, Yang K, Liu Z, Cao S, et al. A next-generation tumor-targeting IL-2 preferentially promotes tumor-infiltrating CD8(+) 
T-cell response and effective tumor control. Nat Commun 2019;10:3874.

45. Motz GT, Santoro SP, Wang LP, Garrabrant T, Lastra RR et al. Tumor endothelium FasL establishes a selective immune barrier promoting tolerance in tumors. Nat Med 2014;20:607-15.

46. Han Y, Chen Z, Yang Y, Jiang Z, Gu Y, et al. Human CD14 CTLA-4 $4^{+}$regulatory dendritic cells suppress T-cell response by cytotoxic T-lymphocyte antigen-4-dependent IL-10 and indoleamine-2,3-dioxygenase production in hepatocellular carcinoma. Hepatology 2014;59:567-79.

47. Shedlock DJ, Shen H. Requirement for CD4 T cell help in generating functional CD8 T cell memory. Science 2003;300:337-9.

48. Borst J, Ahrends T, Babala N, Melief CJM, Kastenmuller W. CD4(+) T cell help in cancer immunology and immunotherapy. Nat Rev Immunol 2018;18:635-47.

49. Benites BD, Alvarez MC, Saad STO. Small particles, big effects: the interplay between exosomes and dendritic cells in antitumor immunity and immunotherapy. Cells 2019;8:1648.

50. Choi YJ, Park SJ, Park YS, Park HS, Yang KM, et al. EpCAM peptide-primed dendritic cell vaccination confers significant anti-tumor immunity in hepatocellular carcinoma cells. PloS one 2018;13:e0190638.

51. Dou L, Ono Y, Chen YF, Thomson AW, Chen XP. Erratum: hepatic dendritic cells, the tolerogenic liver environment, and liver disease. Semin Liver Dis 2018;38:298.

52. Palucka K, Banchereau J. Dendritic-cell-based therapeutic cancer vaccines. Immunity 2013;39:38-48.

53. Sun K, Wang L, Zhang Y. Dendritic cell as therapeutic vaccines against tumors and its role in therapy for hepatocellular carcinoma. Cell Mol Immuno 2006;3:197-203.

54. Chen YX, Man K, Ling GS, Chen Y, Sun BS, et al. A crucial role for dendritic cell (DC) IL-10 in inhibiting successful DCbased immunotherapy: superior antitumor immunity against hepatocellular carcinoma evoked by DC devoid of IL-10. J Immunol 2007;179:6009-15.

55. Beckebaum S, Zhang X, Chen X, Yu Z, Frilling A, et al. Increased levels of interleukin-10 in serum from patients with hepatocellular carcinoma correlate with profound numerical deficiencies and immature phenotype of circulating dendritic cell subsets. Clin Cancer Res 2004;10:7260-9.

56. Perez CR, De Palma M. Engineering dendritic cell vaccines to improve cancer immunotherapy. Nat Commun 2019;10:5408.

57. Peng M, Mo Y, Wang Y, Wu P, Zhang Y, et al. Neoantigen vaccine: an emerging tumor immunotherapy. Mol Cancer 2019;18:128.

58. Gabrilovich DI, Nagaraj S. Myeloid-derived suppressor cells as regulators of the immune system. Nat Rev Immunol 2009;9:162-74.

59. Xu M, Zhao Z, Song J, Lan X, Lu S, et al. Interactions between interleukin-6 and myeloid-derived suppressor cells drive the chemoresistant phenotype of hepatocellular cancer. Exp Cell Res 2017;351:142-49.

60. Guha P, Gardell J, Darpolor J, Cunetta M, Lima M, et al. STAT3 inhibition induces Bax-dependent apoptosis in liver tumor myeloidderived suppressor cells. Oncogene 2019;38:533-48.

61. Sun H, Yang W, Tian Y, Zeng X, Zhou J, et al. An inflammatory-CCRK circuitry drives mTORC1-dependent metabolic and immunosuppressive reprogramming in obesity-associated hepatocellular carcinoma. Nat Commun 2018;9:5214.

62. Li B, Zhang S, Huang N, Chen H, Wang P, et al. CCL9/CCR1 induces myeloidderived suppressor cell recruitment to the spleen in a murine H22 orthotopic hepatoma model. Oncol Rep 2019;41:608-18.

63. Zhou J, Liu M, Sun H, Feng Y, Xu L, et al. Hepatoma-intrinsic CCRK inhibition diminishes myeloid-derived suppressor cell immunosuppression and enhances immune-checkpoint blockade efficacy. Gut 2018;67:931-44.

64. Limagne E, Richard C, Thibaudin M, Fumet JD, Truntzer C, et al. Tim-3/galectin-9 pathway and mMDSC control primary and secondary resistances to PD-1 blockade in lung cancer patients. Oncoimmunology 2019;8:e1564505.

65. Hoechst B, Voigtlaender T, Ormandy L, Gamrekelashvili J, Zhao F, et al. Myeloid derived suppressor cells inhibit natural killer cells in patients with hepatocellular carcinoma via the NKp30 receptor. Hepatology 2009;50:799-807.

66. Hu CE, Gan J, Zhang RD, Cheng YR, Huang GJ. Up-regulated myeloid-derived suppressor cell contributes to hepatocellular carcinoma development by impairing dendritic cell function. Scand J Gastroenterol 2011;46:156-64.

67. Wu CJ, Tsai YT, Lee IJ, Wu PY, Lu LS, et al. Combination of radiation and interleukin 12 eradicates large orthotopic hepatocellular carcinoma through immunomodulation of tumor microenvironment. Oncoimmunology 2018;7:e1477459.

68. Liu M, Zhou J, Liu X, Feng Y, Yang W, et al. Targeting monocyte-intrinsic enhancer reprogramming improves immunotherapy efficacy in hepatocellular carcinoma. Gut 2020;69:365-79.

69. Kang N, Gores GJ, Shah VH. Hepatic stellate cells: partners in crime for liver metastases? Hepatology 2011;54:707-13.

70. Amann T, Bataille F, Spruss T, Muhlbauer M, Gabele E, et al. Activated hepatic stellate cells promote tumorigenicity of hepatocellular carcinoma. Cancer Sci 2009;100:646-53.

71. Neaud V, Faouzi S, Guirouilh J, Le Bail B, Balabaud C, et al. Human hepatic myofibroblasts increase invasiveness of hepatocellular carcinoma cells: evidence for a role of hepatocyte growth factor. Hepatology 1997;26:1458-66.

72. Amin DN, Hida K, Bielenberg DR, Klagsbrun M. Tumor endothelial cells express epidermal growth factor receptor (EGFR) but not ErbB3 and are responsive to EGF and to EGFR kinase inhibitors. Cancer Res 2006;66:2173-80.

73. Rolny C, Nilsson I, Magnusson P, Armulik A, Jakobsson L, et al. Platelet-derived growth factor receptor-beta promotes early endothelial cell differentiation. Blood 2006;108:1877-86.

74. Limmer A, Ohl J, Kurts C, Ljunggren HG, Reiss Y, et al. Efficient presentation of exogenous antigen by liver endothelial cells to CD8+ T cells results in antigen-specific T-cell tolerance. Nat Med 2000;6:1348-54.

75. Bilzer M, Roggel F, Gerbes AL. Role of Kupffer cells in host defense and liver disease. Liver Int 2006;26:1175-86.

76. Ramaiah SK, Rittling S. Pathophysiological role of osteopontin in hepatic inflammation, toxicity, and cancer. Toxicol Sci 2008;103:4-13.

77. Cressman DE, Greenbaum LE, DeAngelis RA, Ciliberto G, Furth EE, et al. Liver failure and defective hepatocyte regeneration in interleukin-6-deficient mice. Science 1996;274:1379-83.

78. Zhang M, Xu S, Han Y, Cao X. Apoptotic cells attenuate fulminant hepatitis by priming Kupffer cells to produce interleukin-10 
through membrane-bound TGF-beta. Hepatology 2011;53:306-16.

79. Hong Y, Peng Y, Guo ZS, Guevara-Patino J, Pang J, et al. Epitope-optimized alpha-fetoprotein genetic vaccines prevent carcinogeninduced murine autochthonous hepatocellular carcinoma. Hepatology 2014;59:1448-58.

80. Bei R, Mizejewski GJ. Alpha fetoprotein is more than a hepatocellular cancer biomarker: from spontaneous immune response in cancer patients to the development of an AFP-based cancer vaccine. Curr Mol Med 2011;11:564-81.

81. Nakagawa H, Mizukoshi E, Kobayashi E, Tamai T, Hamana H, et al. Association between high-avidity T-cell receptors, induced by alpha-fetoprotein-derived peptides, and anti-tumor effects in patients with hepatocellular carcinoma. Gastroenterology 2017;152:1395406.e10.

82. Zhang W, Liu J, Wu Y, Xiao F, Wang Y, et al. Immunotherapy of hepatocellular carcinoma with a vaccine based on xenogeneic homologous alpha fetoprotein in mice. Biochem Biophys Res Commun 2008;376:10-4.

83. Chen $\mathrm{K}$, Wu Z, Zhao H, Wang Y, Ge Y, et al. XCL1/Glypican-3 fusion gene immunization generates potent antitumor cellular immunity and enhances anti-PD-1 efficacy. Cancer Immunol Res 2020;8:81-93.

84. Sawada Y, Yoshikawa T, Nobuoka D, Shirakawa H, Kuronuma T, et al. Phase I trial of a glypican-3-derived peptide vaccine for advanced hepatocellular carcinoma: immunologic evidence and potential for improving overall survival. Clin Cancer Res 2012;18:3686-96.

85. Nakayama J, Tahara H, Tahara E, Saito M, Ito K, et al. Telomerase activation by hTRT in human normal fibroblasts and hepatocellular carcinomas. Nat Genet 1998;18:65-8.

86. Harrington L, Zhou W, McPhail T, Oulton R, Yeung DS, et al. Human telomerase contains evolutionarily conserved catalytic and structural subunits. Genes Dev 1997;11:3109-15.

87. Mizukoshi E, Nakamoto Y, Marukawa Y, Arai K, Yamashita T, et al. Cytotoxic T cell responses to human telomerase reverse transcriptase in patients with hepatocellular carcinoma. Hepatology 2006;43:1284-94.

88. Mizukoshi E, Nakagawa H, Kitahara M, Yamashita T, Arai K, et al. Immunological features of T cells induced by human telomerase reverse transcriptase-derived peptides in patients with hepatocellular carcinoma. Cancer Lett 2015;364:98-105.

89. Bricard G, Bouzourene H, Martinet O, Rimoldi D, Halkic N, et al. Naturally acquired MAGE-A10- and SSX-2-specific CD8+ T cell responses in patients with hepatocellular carcinoma. J Immunol 2005;174:1709-16.

90. Dhodapkar MV, Steinman RM, Krasovsky J, Munz C, Bhardwaj N. Antigen-specific inhibition of effector T cell function in humans after injection of immature dendritic cells. J Exp Med 2001;193:233-8.

91. Schuler-Thurner B, Schultz ES, Berger TG, Weinlich G, Ebner S, et al. Rapid induction of tumor-specific type 1 T helper cells in metastatic melanoma patients by vaccination with mature, cryopreserved, peptide-loaded monocyte-derived dendritic cells. J Exp Med 2002;195:1279-88.

92. Chen C, Ma YH, Zhang YT, Zhang F, Zhou N, et al. Effect of dendritic cell-based immunotherapy on hepatocellular carcinoma: a systematic review and meta-analysis. Cytotherapy 2018;20:975-89.

93. Lu Z, Zuo B, Jing R, Gao X, Rao Q, et al. Dendritic cell-derived exosomes elicit tumor regression in autochthonous hepatocellular carcinoma mouse models. J Hepatol 2017;67:739-48.

94. Wilgenhof S, Corthals J, Heirman C, van Baren N, Lucas S, et al. Phase Ii study of autologous monocyte-derived mRNA electroporated dendritic cells (TriMixDC-MEL) plus ipilimumab in patients with pretreated advanced melanoma. J Clin Oncol 2016;34:1330-8.

95. Lee JH, Lee Y, Lee M, Heo MK, Song JS, et al. A phase I/IIa study of adjuvant immunotherapy with tumour antigen-pulsed dendritic cells in patients with hepatocellular carcinoma. Br J Cancer 2015;113:1666-76.

96. Nemunaitis J, Barve M, Orr D, Kuhn J, Magee M, et al. Summary of bi-shRNA/GM-CSF augmented autologous tumor cell immunotherapy (FANG) in advanced cancer of the liver. Oncology 2014;87:21-9.

97. Pexa-Vec/Nexavar Combination Fails Phase III Trial in Liver Cancer. Available from: https://www.genengnews.com/news/pexa-vecnexavar-combination-fails-phase-iii-trial-in-liver-cancer/ [Last accessed on 21 Apr 2020]

98. Mahipal A, Tella SH, Kommalapati A, Lim A, Kim R. Immunotherapy in hepatocellular carcinoma: is there a light at the end of the tunnel? Cancers (Basel) 2019;11:1078.

99. Yoo SY, Jeong SN, Kang DH, Heo J. Evolutionary cancer-favoring engineered vaccinia virus for metastatic hepatocellular carcinoma. Oncotarget 2017;8:71489-99.

100. Ady JW, Heffner J, Mojica K, Johnsen C, Belin LJ, et al. Oncolytic immunotherapy using recombinant vaccinia virus GLV-1h68 kills sorafenib-resistant hepatocellular carcinoma efficiently. Surgery 2014;156:263-9.

101. Wang J, Xu L, Zeng W, Hu P, Zeng M, et al. Treatment of human hepatocellular carcinoma by the oncolytic herpes simplex virus G47delta. Cancer Cell Int 2014;14:83.

102. Twumasi-Boateng K, Pettigrew JL, Kwok YYE, Bell JC, Nelson BH. Oncolytic viruses as engineering platforms for combination immunotherapy. Nat Rev Cancer 2018;18:419-32.

103. Haanen JB, Robert C. Immune checkpoint inhibitors. Prog Tumor Res 2015;42:55-66.

104. Meng X, Huang Z, Teng F, Xing L, Yu J. Predictive biomarkers in PD-1/PD-L1 checkpoint blockade immunotherapy. Cancer Treat Rev 2015;41:868-76.

105. Sangro B, Gomez-Martin C, de la Mata M, Inarrairaegui M, Garralda E, et al. A clinical trial of CTLA-4 blockade with tremelimumab in patients with hepatocellular carcinoma and chronic hepatitis C. J Hepatol 2013;59:81-8.

106. Zhang M, Pang HJ, Zhao W, Li YF, Yan LX, et al. VISTA expression associated with CD8 confers a favorable immune microenvironment and better overall survival in hepatocellular carcinoma. BMC Cancer 2018;18:511.

107. Prieto J, Melero I, Sangro B. Immunological landscape and immunotherapy of hepatocellular carcinoma. Nat Rev Gastroenterol Hepato 2015;12:681-700.

108. Li H, Wu K, Tao K, Chen L, Zheng Q, et al. Tim-3/galectin-9 signaling pathway mediates T-cell dysfunction and predicts poor 
prognosis in patients with hepatitis B virus-associated hepatocellular carcinoma. Hepatology 2012;56:1342-51.

109. Woo SR, Turnis ME, Goldberg MV, Bankoti J, Selby M, et al. Immune inhibitory molecules LAG-3 and PD-1 synergistically regulate T-cell function to promote tumoral immune escape. Cancer Res 2012;72:917-27.

110. Krummel MF, Allison JP. CD28 and CTLA-4 have opposing effects on the response of T cells to stimulation. J Exp Med 1995;182:459-65.

111. van der Merwe PA, Bodian DL, Daenke S, Linsley P, Davis SJ. CD80 (B7-1) binds both CD28 and CTLA-4 with a low affinity and very fast kinetics. J Exp Med 1997;185:393-403.

112. Qureshi OS, Zheng Y, Nakamura K, Attridge K, Manzotti C, et al. Trans-endocytosis of CD80 and CD86: a molecular basis for the cell-extrinsic function of CTLA-4. Science 2011;332:600-3.

113. Duffy AG, Ulahannan SV, Makorova-Rusher O, Rahma O, Wedemeyer H, et al. Tremelimumab in combination with ablation in patients with advanced hepatocellular carcinoma. J Hepatol 2017;66:545-51.

114. Keir ME, Butte MJ, Freeman GJ, Sharpe AH. PD-1 and its ligands in tolerance and immunity. Annu Rev Immunol 2008;26:677-704.

115. Okazaki T, Honjo T. PD-1 and PD-1 ligands: from discovery to clinical application. Int Immunol 2007;19:813-24.

116. Bardhan K, Anagnostou T, Boussiotis VA. The PD1:PD-L1/2 Pathway from Discovery to Clinical Implementation. Front Immunol 2016;7:550.

117. Iwai Y, Ishida M, Tanaka Y, Okazaki T, Honjo T, et al. Involvement of PD-L1 on tumor cells in the escape from host immune system and tumor immunotherapy by PD-L1 blockade. Proc Natl Acad Sci U S A 2002;99:12293-7.

118. El-Khoueiry AB, Sangro B, Yau T, Crocenzi TS, Kudo M, et al. Nivolumab in patients with advanced hepatocellular carcinoma (CheckMate 040): an open-label, non-comparative, phase 1/2 dose escalation and expansion trial. Lancet 2017;389:2492-502.

119. Kudo M, Matilla A, Santoro A, Melero I, Gracian AC, et al. Checkmate-040: Nivolumab (NIVO) in patients (pts) with advanced hepatocellular carcinoma (aHCC) and Child-Pugh B (CPB) status. J Clin Oncol 2019;37:327-2.

120. Zhu AX, Finn RS, Edeline J, Cattan S, Ogasawara S, et al. Pembrolizumab in patients with advanced hepatocellular carcinoma previously treated with sorafenib (KEYNOTE-224): a non-randomised, open-label phase 2 trial. Lancet Oncol 2018;19:940-52.

121. Finn RS, Ryoo BY, Merle P, Kudo M, Bouattour M, et al. Pembrolizumab as second-line therapy in patients with advanced hepatocellular carcinoma in KEYNOTE-240: a randomized, double-blind, phase III trial. J Clin Oncol 2020;38:193-202.

122. Stein S, Pishvaian MJ, Lee MS, Lee KH, Hernandez S, et al. Safety and clinical activity of $1 \mathrm{~L}$ atezolizumab + bevacizumab in a phase Ib study in hepatocellular carcinoma (HCC). J Clin Oncol 2018;36:4074-74.

123. Xiang J, Zhang N, Sun H, Su L, Zhang C, et al. Disruption of SIRT7 Increases the Efficacy of Checkpoint Inhibitor via MEF2D Regulation of PD-L1 in Hepatocellular Carcinoma Cells. Gastroenterology 2020;158:664-78.e24.

124. Nakamoto N, Cho H, Shaked A, Olthoff K, Valiga ME, et al. Synergistic reversal of intrahepatic HCV-specific CD8 T cell exhaustion by combined PD-1/CTLA-4 blockade. PLoS Pathog 2009;5:e1000313.

125. Aregay A, Owusu Sekyere S, Deterding K, Port K, Dietz J, et al. Elimination of hepatitis C virus has limited impact on the functional and mitochondrial impairment of HCV-specific CD8 ${ }^{+} \mathrm{T}$ cell responses. J Hepatol 2019;71:889-99.

126. Stein S, Pishvaian MJ, Lee MS, Lee KH, Hernandez S, et al. Safety and clinical activity of 1L atezolizumab plus bevacizumab in a phase Ib study in hepatocellular carcinoma (HCC). J Clin Oncol 2018;36.

127. Baxi S, Yang A, Gennarelli RL, Khan N, Wang Z, et al. Immune-related adverse events for anti-PD-1 and anti-PD-L1 drugs: systematic review and meta-analysis. BMJ 2018;360:k793.

128. Moslehi JJ, Salem JE, Sosman JA, Lebrun-Vignes B, Johnson DB. Increased reporting of fatal immune checkpoint inhibitor-associated myocarditis. Lancet 2018;391:933.

129. Chmielewski M, Hombach AA, Abken H. Antigen-specific T-cell activation independently of the MHC: chimeric antigen receptorredirected T cells. Front Immunol 2013;4:371.

130. Ramos CA, Dotti G. Chimeric antigen receptor (CAR)-engineered lymphocytes for cancer therapy. Expert Opin Biol Ther 2011;11:855-73.

131. Gao HP, Li KS, Tu H, Pan XR, Jiang H, et al. Development of T cells redirected to glypican-3 for the treatment of hepatocellular carcinoma. Clin Cancer Res 2014;20:6418-28.

132. Liu Y, Di S, Shi B, Zhang H, Wang Y, et al. Armored inducible expression of IL-12 enhances antitumor activity of glypican-3-targeted chimeric antigen receptor-engineered T cells in hepatocellular carcinoma. J Immunol 2019;203:198-207.

133. Chen C, Li K, Jiang H, Song F, Gao H, et al. Development of T cells carrying two complementary chimeric antigen receptors against glypican-3 and asialoglycoprotein receptor 1 for the treatment of hepatocellular carcinoma. Cancer Immunol Immunother 2017;66:475-89.

134. Zhai B, Shi D, Gao H, Qi X, Jiang H, et al. A phase I study of anti-GPC3 chimeric antigen receptor modified T cells (GPC3 CAR-T) in Chinese patients with refractory or relapsed GPC3 ${ }^{+}$hepatocellular carcinoma ( $\mathrm{r} / \mathrm{r} \mathrm{GPC}^{+}{ }^{\mathrm{HCC}}$ ). J Clin Oncol 2017;35:3049-49.

135. MacKay M, Afshinnekoo E, Rub J, Hassan C, Khunte M, et al. The therapeutic landscape for cells engineered with chimeric antigen receptors. Nat Biotechnol 2020;38:233-44.

136. Rafiq S, Hackett CS, Brentjens RJ. Engineering strategies to overcome the current roadblocks in CAR T cell therapy. Nat Rev Clin Oncol 2020;17:147-67.

137. Gao XC, Mi YJ, Guo N, Xu H, Xu LX, et al. Cytokine-induced killer cells as pharmacological tools for cancer immunotherapy. Front Immunol 2017;8:774.

138. Mata-Molanes JJ, Gonzalez MS, Jimenez BV, Navarro EMM, Masllorens AB. Cancer immunotherapy with cytokine-induced killer cells. Target Oncol 2017;12:289-99.

139. Pan QZ, Wang QJ, Dan JQ, Pan K, Li YQ, et al. A nomogram for predicting the benefit of adjuvant cytokine-induced killer cell immunotherapy in patients with hepatocellular carcinoma. Sci Rep 2015;5:9202.

140. Lee JH, Lee JH, Lim YS, Yeon JE, Song TJ, et al. Adjuvant immunotherapy with autologous cytokine-induced killer cells for 
hepatocellular carcinoma. Gastroenterology 2015;148:1383-91.e6.

141. Huang ZM, Li W, Li S, Gao F, Zhou QM, et al. Cytokine-induced killer cells in combination with transcatheter arterial chemoembolization and radiofrequency ablation for hepatocellular carcinoma patients. J Immunother 2013;36:287-93.

142. Yu X, Zhao H, Liu L, Cao S, Ren B, et al. A randomized phase II study of autologous cytokine-induced killer cells in treatment of hepatocelluar carcinoma. J Clin Immunol 2014;34:194-203.

143. Yu SJ, Ma C, Heinrich B, Brown ZJ, Sandhu M, et al. Targeting the crosstalk between cytokine-induced killer cells and myeloidderived suppressor cells in hepatocellular carcinoma. J Hepatol 2019;70:449-57.

144. Jiang SS, Tang Y, Zhang YJ, Weng DS, Zhou ZG, et al. A phase I clinical trial utilizing autologous tumor-infiltrating lymphocytes in patients with primary hepatocellular carcinoma. Oncotarget 2015;6:41339-49.

145. Takayama T, Sekine T, Makuuchi M, Yamasaki S, Kosuge T, et al. Adoptive immunotherapy to lower postsurgical recurrence rates of hepatocellular carcinoma: a randomised trial. Lancet 2000;356:802-7.

146. Zhou G, Sprengers D, Boor PPC, Doukas M, Schutz H, et al. Antibodies against immune checkpoint molecules restore functions of tumor-infiltrating t cells in hepatocellular carcinomas. Gastroenterology 2017;153:1107-19.e10.

147. Mossanen JC, Kohlhepp M, Wehr A, Krenkel O, Liepelt A, et al. CXCR6 inhibits hepatocarcinogenesis by promoting natural killer Tand CD4(+) T-cell-dependent control of senescence. Gastroenterology 2019;156:1877-89.e4.

148. Kamiya T, Chang YH, Campana D. Expanded and activated natural killer cells for immunotherapy of hepatocellular carcinoma. Cancer Immunol Res 2016;4:574-81.

149. Tan S, Xu Y, Wang Z, Wang T, Du X, et al. Tim-3 hampers tumor surveillance of liver resident and conventional NK cells by disrupting PI3K signaling. Cancer Res 2020;80:1130-42. 